\title{
Policy Brief: Departmental Policies to Improve Mentorship for Graduate Students
}

\author{
Aliya R. Hoff \\ School of Human Evolution and Social Change, Arizona State University \\ aliya.hoff@asu.edu
}

\section{Executive Summary}

The relationship between an advisor and student is one of the most important factors in predicting graduate student outcomes, yet the vast majority of faculty never participate in formal mentorship training. Furthermore, few mechanisms of accountability exist to assess the quality of mentorship that graduate students receive. Departmental leadership must take responsibility for graduate student success by enacting policies and structures to ensure all students receive effective and equitable mentorship. I recommend that departments reward effective mentorship in performance evaluations and hiring, tenure, and promotion decisions. Providing incentives to develop mentorship competencies will catalyze faculty adoption of recommended best practices.

\section{Problem Definition}

Recent reports published by the National Academies of Science, Engineering, and Medicine (NASEM) and others call for substantial reforms of graduate education due to high levels of attrition, concern for students' mental health, and persistent racial disparities in student outcomes. ${ }^{1}$ To meet projected demands for an educated workforce capable of addressing increasingly urgent global challenges, ${ }^{2}$ universities simply cannot afford to admit homogeneous student cohorts or lose talented graduate students they invest in. Despite research demonstrating

\footnotetext{
${ }^{1}$ See, e.g., NASEM 2018a, 2018b, 2019, 2021; Davis et al. 2020

${ }^{2}$ NASEM $2018 \mathrm{a}$
} 
that mentoring relationships are a key predictor of graduate student outcomes, ${ }^{3}$ many faculty practice "ad hoc" mentorship instead of intentionally developing their mentoring competencies through continuing education, routine assessment, and constructive feedback (NASEM, 2019, pp.185-186). ${ }^{4}$ First generation and minoritized students lacking social capital are disproportionately disadvantaged by status quo mentoring practices that place sole responsibility for success on the student. ${ }^{5}$ Departmental leaders are key stakeholders who can enact policies and structures to ensure effective and equitable mentorship for graduate students. In this policy memorandum, I discuss three interventions departments can enact to improve mentorship of graduate students and evaluate them in terms of administrative, political, and economic feasibility and potential to advance equity.

\section{Policy Options}

\section{Option A: Require Annual Mentoring Training for All Department Members}

Departments should require all members to complete evidence-based, culturally responsive mentoring training annually. Departments may promote existing university workshops, hire external facilitators to lead on-site workshops, fund members to complete facilitator training in exchange for leading departmental workshops ${ }^{6}$, or offer funding to attend external workshops.

\footnotetext{
${ }^{3}$ See Lovitts (2002) and Sverdlik et al. (2018).

${ }^{4}$ NASEM defines mentorship as a "professional, working alliance in which individuals work together over time to support the personal and professional growth, development, and success of the relational partners through the provision of career and psychosocial support," (2019, pp. 8). Career support involves career guidance, skill development, and sponsorship; psychosocial support includes role modeling and providing psychological and emotional support to navigate stressors (NASEM, 2019, pp.8). NASEM attributes reliance on "ad hoc mentoring" to a lack of time, resources, and incentives available to mentors (2019, pp. 7).

${ }^{5}$ According to NASEM, "current mentoring systems [in STEMM] are structured to benefit...White, male, heteronormative, continuing generation, and upper or middle class [students]" (2019, pp. 4).

${ }^{6}$ Sponsoring members to become facilitators is a cost-effective way to ensure workshops are tailored to meet the needs of the department with relatively low administrative burden.
} 


\section{Advantages}

Studies have demonstrated that mentoring training is effective for participants of all experience levels. ${ }^{7}$ Effective mentorship increases graduate student productivity, persistence, and completion rate and may particularly benefit first generation and minoritized students. ${ }^{8}$ Mentorship training is therefore cost-effective because it may reduce the attrition of students the department has already invested in.

\section{Disadvantages}

Faculty may be resistant to imposing mandatory requirements on their peers, especially if it requires departmental funds. Disparities in mentorship quality may persist if there are no incentives to routinely employ the tools introduced by the training. Thus, political feasibility and equity outcomes may be limited if additional mentorship policies are not adopted.

\section{Option B: Clearly Define Mentoring Expectations, Tools, and Processes}

In addition to defining academic requirements, processes for selecting an advisor, and expectations for graduate student conduct, departments should provide explicit expectations for faculty mentors. At a minimum, departments should:

- Define baseline mentoring expectations of all faculty advisors and provide examples of recommended and inappropriate conduct in mentoring relationships. ${ }^{9}$

- Explain the rationale for using evidence-based mentoring tools. ${ }^{10}$

\footnotetext{
${ }^{7}$ According to Stolzenberg and colleagues (2019), only 7\% of faculty who responded to the 2016-2017 HERI faculty survey reported participating in substantive mentorship training. For studies on mentorship training efficacy, see Butz et al. (2018), Byars-Winston et al. (2018), Lewis et al. (2016), and Pfund et al. (2013). A particularly well-studied training is the Entering Mentoring program (Handelsman et al., 2005; Pfund et al., 2006; Pfund et al., 2015).

${ }^{8}$ See Lunsford (2012) for graduate student productivity and degree completion, McGree and Keller (2007) for graduate student persistence, Lewis et al. (2016) and Byars-Winston et al. (2016) on mentorship effects for minoritized undergraduate students.

${ }^{9}$ For examples of faculty mentoring guidelines and statements, see UC Davis (n.d.), University of Arizona (n.d.), and Mentoring Future Scientists (n.d.).

${ }^{10}$ Examples of mentoring tools include mentorship compacts (Association of American Medical Colleges, 2017), mentoring maps (Montgomery, 2017), and Individual Development Plans (see the NASEM 2019 companion website for more information: https://www.nap.edu/resource/25568/interactive/tools-and-resources.html\#section2).
} 
- Describe protocols for addressing negative mentoring experiences. ${ }^{11}$

\section{Advantages}

Graduate program handbooks are an ideal starting point to define mentoring policies because they can often be revised quickly with minimal administrative burden (Alexander et al., n.d., pp. 3-4). This option will particularly benefit first generation and minoritized students by demystifying the "hidden curriculum."12 Defining mentoring expectations and processes helps students navigate power differentials, identify problematic behavior, and decide when and how to seek support.

\section{Disadvantages}

The relative ease of revising graduate program handbooks is also a limitation. If the handbook can be revised at the discretion of a department chair/committee without approval via faculty vote, the guidelines may lack accountability mechanisms and faculty support, undermining the intervention's efficacy and longevity and displacing the responsibility to advocate for quality mentorship onto graduate students.

\section{Option C: Reward Effective Mentorship in Faculty Evaluation Processes}

Departments can incentivize developing mentoring competencies by rewarding effective mentorship in performance evaluations and hiring, tenure, and promotion decisions. Faculty commonly report mentorship activities in terms of co-authored publications or mentee achievement (awards, degree milestones, job placement). In addition to those measures, departments can require faculty to submit $\mathrm{a}(\mathrm{n})$ :

\footnotetext{
${ }^{11}$ E.g., list reporting options and contact information for neutral third-parties in the department/university, explain how the department will investigate and address reports of negative experiences, detail the process for dissolving a mentoring relationship and the steps the department will take to protect the student from potential retaliation (e.g., Department of Chemistry and Biochemistry, 2019) and clarify how departments will report faculty misconduct to funding agencies. For more on negative mentoring experiences see Chapter 5 of NASEM (2019) and Tuma and colleagues (2021).

${ }^{12}$ The "hidden curriculum" refers to the tacit norms and values that underlie expectations of how academics should think and behave (Margois \& Romero 1998).
} 
- Separate mentoring statement that describes their approach to mentoring graduate students $^{13}$

- Document that describes their research group's work culture and expectations ${ }^{14}$

- Annual self-evaluation of how they developed their mentoring competencies and their plan to address perceived areas of weakness

In addition to requiring routine self-reflection, departments should establish formal processes to solicit feedback from mentees and peers to document, assess, and develop faculty mentoring competencies.

\section{Advantages}

Option $\mathrm{C}$ encourages intentional rather than ad hoc mentorship, rewards faculty who are already striving to provide high-quality mentorship, and establishes consequences for negligent or harmful advisors to better protect students. Thus, it has the greatest potential to advance equity by establishing lasting mechanisms of accountability.

\section{Disadvantages}

Since changes to department-level faculty evaluations generally require amending bylaws, this option requires a moderate to high administrative burden and may have limited political feasibility in departments where faculty do not prioritize mentoring or are resistant to opening their mentoring practices to critique.

\footnotetext{
${ }^{13}$ Mentoring is often combined with teaching activities in faculty evaluations; satisfactory teaching may therefore outweigh poor mentorship quality.

${ }^{14}$ See Masters and Kreeger (2017) for tips on how to draft expectation documents. Those documents can be reviewed for potentially exclusionary practices or inconsistencies with department or university policy.
} 


\section{Policy Recommendation}

While the first two options can be implemented relatively quickly without substantial administrative burden or political resistance, I recommend prioritizing Option C. Assessing mentorship competency in faculty evaluations will have a cascading effect that will increase the adoption of other recommendations because faculty will become invested in obtaining training and defining clear expectations. I recommend a phased implementation of Option C, beginning with mentorship evaluation in faculty hiring and annual reviews of graduate students. ${ }^{15}$

- Search committees can pilot rubrics to assess mentorship competency as a key criterion for hiring decisions.

- Evaluation of graduate students can become a reciprocal process whereby faculty submit a reflective self-assessment of their mentoring competency and identify areas for growth, and students can provide feedback about mentoring quality. ${ }^{16}$

Once systems of feedback and evaluation have been tested and revised, departments will be in a better position to implement policy changes that require approval via a majority vote so that mentoring is evaluated as a distinct criterion during faculty performance reviews ${ }^{17}$ and unit-level recommendations for promotion and tenure. Revising promotion criteria can be implemented first to increase tenured faculty's investment in mentoring. Criteria for unit-level tenure decisions should be revised last to avoid shifting expectations for faculty currently seeking tenure. By implementing Option C, tenured faculty—rather than vulnerable graduate students—-will drive

\footnotetext{
${ }^{15}$ Department and committee chairs tend to have some discretion in both processes, and faculty are likely to be more comfortable, at least initially, evaluating applicants and students than evaluating their peers.

${ }^{16}$ Departments should provide the option to provide mentoring feedback anonymously. However, a student's resistance to offering feedback may signal a problematic mentoring relationship. The quality of mentorship received should be taken into account when evaluating whether a student is making satisfactory degree progress.

${ }^{17}$ An unsatisfactory mentorship evaluation could trigger a performance improvement plan; continued deficiencies might result in a probationary period where faculty cannot take on additional students and/or trigger a post-tenure review.
} 
demand for improving mentorship and serve as a model for peer departments/institutions to adopt similar accountability mechanisms to support and protect graduate students. 


\section{References}

Alexander, S., Anderson, S., Bratburd, J., Canales, A., \& Lynch, T. (n.d.). Advocating for an improved graduate education learning environment: Case study survey of graduate handbook policies and procedures at the University of Wisconsin-Madison. Catalysts for Science Policy, $1-27$.

Association of American Medical Colleges. (2017). Compact Between Biomedical Graduate Students and Their Research Advisors. Retrieved April 5, 2021, from https://www.aamc.org/what-we-do/mission-areas/medical-research/grad-compact.

Butz, A., J. Branchaw, C. Pfund, A. Byars-Winston, \& P. Leverett. (2018). Promoting STEM trainee research self-efficacy: A mentor training intervention. Understanding Interventions Journal, 9(1).

Byars-Winston, A., J. Rogers, J. Branchaw, C. Pribbenow, R. Hanke, \& C. Pfund. (2016). New measures assessing predictors of academic persistence for historically underrepresented racial/ethnic undergraduates in science. CBE-Life Sciences Education, 15(3).

Byars-Winston, A., V. Y. Womack, A. R. Butz, R. McGee, S. C. Quinn, E. Utzerath, C. L. Saetermoe, \& S. Thomas. (2018). Pilot study of an intervention to increase cultural awareness in research mentoring: Implications for diversifying the scientific workforce. Journal of Clinical and Translational Science, 2(2), 86-94.

Davis, S. M., Singh, H., Weismann, C. M., Bankston, A., \& Sancheznieto, F. (2020). Actionable recommendations from trainees to improve science training. ELife, 9.

https://doi.org/10.7554/eLife.59806

Department of Chemistry and Biochemistry, University of Maryland. (2019). Dissolution of a Graduate Student/Faculty Advisor Research Relationship.

http://www.chem.umd.edu/wp-content/uploads/2009/07/DissolutionPolicy1.pdf

Handelsman, J., C. Pfund, S. M. Lauffer, \& C. M. Pribbenow. (2005). Entering mentoring: A seminar to train a new generation of scientists. Madison, WI: University of Wisconsin Press.

Margolis, E., \& M. Romero. (1998). "The department is very male, very white, very old, and very conservative: the functioning of the hidden curriculum in graduate sociology departments." Harvard Educational Review, 68(1), 1-33.

Lewis, V., C. A. Martina, M. P. McDermott, P. M. Trief, S. R. Goodman, G. D. Morse, J. G. LaGuardia, D. Sharp, \& R. M. Ryan. (2016). A randomized controlled trial of mentoring interventions for underrepresented minorities. Academic Medicine 91(7), 994-1001.

Lovitts, B. E. (2002). Leaving the ivory tower: The causes and consequences of departure from doctoral study. Lanham, MD: Rowman \& Littlefield. 
Lunsford, L. (2012). Doctoral advising or mentoring? Effects on student outcomes. Mentoring \& Tutoring: Partnership in Learning, 20(2), 251-270.

Masters, K. S., \& Kreeger, P. K. (2017). Ten simple rules for developing a mentor-mentee expectations document. PLOS Computational Biology, 13(9).

https://doi.org/10.1371/journal.pcbi.1005709

McGee, R., \& Keller, J. L. (2007). Identifying future scientists: Predicting persistence into research training. CBE-Life Sciences Education, 6(4). https://doi.org/10.1187/cbe.07-04-0020

Mentoring Future Scientists. (n.d.). Mentoring Climate Guidelines. Retrieved April 5, 2021, from https://mentoringfuturesci.net/.

Montgomery, B. L. (2017). Mapping a Mentoring Roadmap and Developing a Supportive Network for Strategic Career Advancement. SAGE Open, 7(2). https://doi.org/10.1177/2158244017710288

National Academies of Sciences, Engineering, and Medicine. (2018a). Graduate STEM education for the 21st century. Washington, DC: The National Academies Press.

National Academies of Sciences, Engineering, and Medicine. (2018b). Sexual Harassment of Women: Climate, Culture, and Consequences in Academic Sciences, Engineering, and Medicine. Washington, DC: The National Academies Press.

National Academies of Sciences, Engineering, and Medicine. (2019). The Science of Effective Mentorship in STEMM. Washington, DC: The National Academies Press. https://doi.org/10.17226/25568

National Academies of Sciences, Engineering, and Medicine. (2021). Mental Health, Substance Use, and Wellbeing in Higher Education: Supporting the Whole Student. Washington, DC: The National Academies Press. https://doi.org/10.17226/26015

Pfund, C., J. L. Branchaw, \& J. Handelsman. (2015). Entering mentoring version 2. New York, NY: W. H. Freeman.

Pfund, C., S. House, K. Spencer, P. Asquith, P. Carney, K. S. Masters, R. McGee, J. Shanedling, S. Vecchiarelli, \& M. Fleming. (2013). A research mentor training curriculum for clinical and translational researchers. Clinical and Translational Science 6(1), 26-33.

Pfund, C., C. Maidl Pribbenow, J. Branchaw, S. Miller Lauffer, \& J. Handelsman. (2006). The merits of training mentors. Science 311(5760), 473-474.

Stolzenberg, E. B., K. Eagan, H. B. Zimmerman, J. B. Lozano, N. M. Cesar-Davis, M. C. Aragon, \& C. Rios-Aguilar. (2019). Undergraduate teaching faculty: The HERI faculty survey 2016-2017. Los Angeles, CA: University of California, Los Angeles. 
Sverdlik, A., Hall, N. C., McAlpine, L., \& Hubbard, K. (2018). The PhD experience: A review of the factors influencing doctoral students' completion, achievement, and well-being. International Journal of Doctoral Studies, 13, 361-388. https://doi.org/10.28945/4113

Tuma, T. T., Adams, J. D., Hultquist, B. C., \& Dolan, E. L. (2021). The Dark Side of Development: A Systems Characterization of the Negative Mentoring Experiences of Doctoral Students. CBE-Life Sciences Education, 20(2). https://doi.org/10.1187/cbe.20-10-0231

UC Davis Graduate Council. (n.d.) Mentoring Guidelines. Retrieved April 5, 2021, from https://grad.ucdavis.edu/sites/default/files/upload/files/grad-council/mentoring.pdf

University of Arizona College of Science: Psychology. (n.d.). An Aspirational Statement on Faculty Mentorship. Retrieved April 5, 2021, from https://psychology.arizona.edu/faculty-mentorship 